\title{
Risk of the building deformation because of above-permitted standard subsidence
}

\author{
Sergey Chernyshev ${ }^{1}$, Andrey Lavrusevich ${ }^{1, *}$, and Aleksey Martynov ${ }^{1}$ \\ ${ }^{1}$ Moscow State University of Civil Engineering, 129337, 26, Yaroslavskoye Shosse, Moscow, Russia
}

\begin{abstract}
The authors suppose that the vulnerability of natural-andtechnical system in relation to the subsidence can be equated to the financial costs of repair or new construction with the summation of losses from the temporary exception of this system from the economic activity. Then the vulnerability can be considered as the economic damage, and risk can be considered as the multiplication of damage by the probability of a dangerous event. The method of calculation of geological risk is offered in the article and can be applied in practice by geologists, mathematicians and designers.
\end{abstract}

\section{Introduction}

As for the problems of calculation of interaction of buildings and structures with the environment the risk theory has been developed for the first time for the estimation of economic benefit of building in seismic regions [1-4]. Later it was applied for solving other problems, where interaction of environment with probabilistic characteristics with buildings and structures, having determined parametres of structures and cost, is considered. In the form, which is close to the strict mathematical decision of the first works, it was modified with the reference to the problem of calculation of heat-shielding of buildings in the Far North [5].

The risk theory is presented for engineering geology by A.L.Rogozin [6], and also by some foreign researchers [7, 8]. Nowadays the risk-analysis actively develops in engineering geology [7-9]. Recently risk definition has been regulated for engineering researches by standard documents [10].

\section{Materials and methods}

In the risk theory there are some fundamental, but yet not well-settled concepts, which are treated differently: "danger", "vulnerability", "damage", "risk". According to various definitions, available in the literature [9] we accept, that with the reference to rather simple process of subsidence natural-and-technogenic "danger" is the probability of realisation of adverse event. Adverse event can be presented as the considerable deviation of geological border of a weak ground from the border, demonstrated on the engineering-and-geological cut, and as the deviation of the real module of deformation of the ground from the calculated value because of usually statistically insufficient quantity of tests in the engineering-

*Corresponding author: lavrusevich@yandex.ru 
geological element (2-3 experiments according to the Construction Rules 22.13330 from the year 2016). Another cause is the change of characteristics of the ground in the process of construction or construction operation (for example because of soaking). Russian standard documents for the subsidence calculation define the unilateral confidential level of probability as 0.85 for buildings of the "Average" category of responsibility. Thus, the probability of excess the calculated subsidence $S_{c}$ by the actual subsidence $S_{a}$ is $15 \%$. The unilateral probability is accepted, because the reduction of the actual subsidence against the calculated one (as that often happens), does not represent any danger for a structure. In this article we refer to subsidence as any deformations, which are regulated by the Construction Rules 22.13330. 2016 «Bases of buildings and constructions» and which limiting values are specified in this document, for simplicity.

According to A.L. Rogozin, vulnerability is the potential ability of the natural-andtechnical system (NTS) to damages up to failure. Many natural and natural-and-technogenic processes evoke a wide response in the environment and society up to defeat of people in case of damage. Natural or techno-and-natural process can cause mutilations, wounds, death of people or in case of preservation members of society safe they can cause failures in public life, namely violation in the schedule of public transport, supply of citizens with the vital resources. In such cases it is impossible to speak about damage in terms of money. Therefore difficult catastrophic processes, having branched consequences, are hardly described within the theory of risk. Subsidence proceeds slowly, thus it does not cause mutilations and death of people, its impact on the environment is limited to usually small territory, adjacent to the subject. In relation to the subsidence vulnerability can be equated to the financial costs of repair or new construction with the summation of losses because of the temporary exception of the natural-and-technical system (NTS) from the economic activity. Then vulnerability can be equated the economic damage [14].

According to the classical statement $[1,2,5]$ risk is this work of damage on probability of a dangerous event. The seismic risk of $\mathrm{R}$ can be presented as

$$
\mathrm{R}=\mathrm{D}(\mathrm{K}, \mathrm{I}) \cdot \mathrm{L}(\mathrm{I}) \text {, }
$$

Where:

$\mathrm{D}(\mathrm{K}, \mathrm{I})$ - damage for the building, supposed for an earthquake with the intensity $\mathrm{K}$, from an earthquake with the intensity $\mathrm{I}$; it is accepted that $\mathrm{I}>\mathrm{K}$;

L (I) - repeatability of earthquakes of level I on the platform of a building, that is the assessment of probability of a dangerous event.

We shall notice that in case of the excess of intensity on 1 point against the calculated intensity, for example, during 8-mark earthquake in a 7-mark zone, the buildings, supposed to persist at 7 points do not collapse, but they receive damages and they are maintainable. The people, who are in these buildings, do not get serious wounds, if there keep rules of individual protection [12]. The repair cost favourably differs from the construction cost. Because of small probability of a 8-mark earthquake in a 7-mark zone it is not rational to make investments in construction with protection at the level of 8 points. The similar situation takes place during a 7-mark earthquake in a 6-mark zone and a 9-mark earthquake in a 8mark zone. The value of risk $\mathrm{R}$ in the context of fight against earthquakes is the conditional characteristic for the acceptance in each case of making decisions on the level of aseismic protection.

Similar approach can be applied to consideration of subsidence risk. At the same time the first factor of the equation (1) will reflect the damage from the excess subsidence of the building in the form of the sum of costs of repair of the building, and also strengthening of soil and the bases for the purpose of the termination of dangerous process as well as other expenses connected. As for subsidence, the damage will change, depending on the difference $\Delta \mathrm{s}=\mathrm{Sa}-\mathrm{Sc}$. In case of the increase of this difference the damage will increase too, and the 
probability of the achievement of this level of subsidence will decrease. The calculation of the damage as a function of $\Delta \mathrm{s}$ is beyond the geoecology science, as it concerns the cost of design and construction works. We will just note, that at one of our subjects the damage from the subsidence, which exceeded the value, admissible according norms for memorial buildings, by 5 times in some places, made up about 10 million rubles in the prices of 2015 . This damage was caused to a four-storeyed brick house with two entrances. it is equal to real expenses of the house owner, who made strengthening of the bases of all the bearing walls, brought trailing boring-and-injection piles under those parts of the house which independently settled in the investigation ongoing karst and suffosion process, made repair of the asphalt covering of the yard to exclude infiltration of water after raining and snowing. The expense on the facades repair were included into the specified sum, as they were injured by cracks.

The second factor of the equation has to express the total probability of adverse events, which can cause excess subsidence. If determination of value of the first factor is beyond geoecology as it was aforesaid, the determination of value of the second factor is within geoecology. Within it there is also the determination of $\Delta \mathrm{s}=\mathrm{Sa}-\mathrm{Sc}$, which is necessary for calculation D function.

\section{Results}

Experience of summation of adverse effects on natural-and-technical system is presented [5] during selection of a heat-shielding of the building. The authors summarize the risk from some events, which include temperature of external air - 60, - 70, - 80, - 90 and -100. It is obvious, that with transition to the following category of fall of temperature of external air the damage to the temperature inside the building increases, but at the same time the probability of the emergence of such temperature decreases. There is the analogy to our process, in which during the increase of subsidence, the damage increases, but the th probability of an exit of the difference $\Delta$ s to a new level decreases.

In this work [5] the total risk R (h) during long maintenance of the building

$$
\mathrm{R}(\mathrm{h})=\Sigma \mathrm{ID}(\mathrm{h}, \mathrm{I}) \cdot \mathrm{L}(\mathrm{I}) \text {, }
$$

Where:

$\Sigma \mathrm{I}$ - the sign of summation of risks, according to all the categories,

$\mathrm{h}$ - the optimized size, heat-shielding layer thickness in the wall,

L (I) - repeatability of the event of getting the temperature of external air into the interval with average value $\mathrm{I}$.

The risk $\mathrm{R}(\Delta \mathrm{s})$ will also be equal to the sum of risks from some adverse events in our case

$$
\mathrm{R}(\Delta \mathrm{s})=\Sigma \mathrm{nD}(\Delta \mathrm{s}, \mathrm{i}) \cdot \mathrm{L}(\mathrm{i}),
$$

Where:

$\mathrm{n}$ - quantity of the factors, defining an error of calculation of subsidence

$\Delta \mathrm{s}$ - an error of calculation of subsidence because of influence of the fixed the i-th factor among $\mathrm{n}$ factors,

$\mathrm{D}(\Delta \mathrm{s}, \mathrm{i})$ - damage from the excess subsidence of the building by $\Delta \mathrm{s}$, menacing to be in case of influence of the $\mathrm{i}$-th factor.

L (i) - function of the probability of the existence of the i-th factor in a value, causing excess subsidence $\Delta \mathrm{s}$.

Among the i set factors we can mention: the error of carrying out the border, which is the first from the sole of the base of the engineering-geological elements (EGE), the error of carrying out the second border from the sole of the base of border of EGE, the error of carrying out the third border from the sole of the base of border of EGE and so on - to the 
lower bound of the compressed zone; the error of the definition of the module of the general deformation of soil in the first layer from the sole of the base, caused by the inhomogeneity of soil, the same error of definition of the module of the general deformation of soil in the second layer from the sole of the base and so further; errors from the change of modules of the general deformation of EGE in case of external influences which can be soaking of clay soil, change of composition of steam water in them, vibration consolidation of sands, their suffusion the decompaction of the soil.

It was proved [12] that the error of carrying out geological border, as well as the error of geological interpolation, can exceed $1 \mathrm{~m}$, in case of real distance between wells during research. Such error in case of a close arrangement of border to the sole of the base and at sharp change of the module of the soil deformation on the border leads to the significant contribution in $\Delta \mathrm{s}$. According to the results of numerical modelling [13] its contribution in the general error can exceed a half of the calculated value. During removal of the border from the sole of the base up to the depth to the equal threefold width of the base the contribution decreases not linearly to $4 \%$ from the calculated subsidence.

\section{Discussion}

The contribution from fluctuation of the module of deformation within EGE strongly depends on the degree of inhomogeneity of soil and the number of definitions of the module of deformation.

For example, on one of subjects to research (church in the village of Diveevo) 14 experiments were carried out for the definition of the module of the general deformation of Eo for the layer of the uniform integumentary clay . The arithmetic average of 21.6 MPas was received. The standard deviation of the arithmetic average is small, it is equal 1.4 MPas. The confidential interval has borders of $20.2-23.0$ MPas with the probability of $68.3 \%$. The contribution to the error of calculation of subsidence for inaccuracy of definition of the calculated value of the module of the general deformation in this case will make $7 \%$ at the level of reliability of $85 \%$ for another layer on the same subject in which only 6 tests were carried out. The same contribution will reach $16 \%$ at the same reliability of the conclusion of $85 \%$. In case of admissible during research number of definitions 3 and even 2 (according to norms) the contribution from an error of definition of the module of the general deformation will be much more, but it is impossible to estimate it by the methods of mathematical statistics at the number of definitions less than 4. Therefore it is necessary to consider inadmissible definition of the module of the general deformation of EGE on 2-3 samples. There have to be not less than four samples in any case.

Value of L (i) is the function from the probability of achievement by a factor of the contribution to process described above. As it has been told, in relation to subsidence according to norms the level of unilateral confidential probability 0.85 is accepted. At this level the excess of the actual subsidence over the calculated subsidence is possible with the probability of $\mathrm{P}=0.15$.

\section{Conclusion}

Generalizing, we will note: for rather simple process of draft it is obviously possible at further study of a question in common by geologists, designers and mathematicians to find function of risk, to develop the program for her calculation for such arguments as errors of researches, expected numerical characteristics of external impacts on the basis (the forecast of flooding, vibration and chemical influences, karstic суффозионного process), the cost of repair work, including geotechnical works and compensation assignments for temporary non-execution of 
natural-and-technical system of the appointment. It will be function of geological risk, on classification [15] as she won't include risks of draft from low-quality execution of the bases or their technogenic change in the adverse party that happens at illiterate operation of buildings.

So, in the considered simple case, when natural-and-technogenic process is localized in small volume in real physical space, and also in space of public-and-economic life, the calculation of risk represents the difficult and the task, not solved yet, which basic provisions of the decision are provided in the article.

\section{References}

1. V.I. Kejlis-Borok, I.A. Nersesov, A.M. Jaglom, Method of an estimation of economic benefit of aseismic building (Publishing house, Moscow, 1962)

2. L.V. Kantorovich, V.I. Kejlis-Borok, G.I. Molchun, Computing seismology 6, 3-20 (1973)

3. M.A. Bogdanova, V.V. Segidov, Natural and technogenic risks. Safety of constructions 6, 54-57 (2011)

4. M.A. Bogdanova, S.S. Ogneva, A.M. Uzdin, V.P. Chernov, Natural and technogenic risks. Safety of constructions 3, 46-49 (2013)

5. A.M. Uzdin, T.A. Belash, A.A. Iglina, Industrial and civil building 12, 97-100 (2017)

6. A.L. Rogozin, Safety problems in emergency situations 5, 4-21 (1993)

7. Guidelines for preparing geologic reports for regional-scale environmental-andresource management planning (California division of Mines and Geology, 2001)

8. Guideline for Landslide Susceptibility Hazard and Risk Zoning for Land Use Planning, Journal and News of the Australian Geomechanics Society 42-1, 13-36 (2007)

9. A.V. Bershov, Engineering geology of Russia. Volume 2. Engineering geodynamics of territory of Russia (Publishing house KDU, Moscow, 2013)

10. Recommendations according to geological risk in territory of Moscow (Moscomarchitechtura, Moscow, 2002)

11. A.D. Potapov, S.N. Revelis, Earthquake. The reasons, consequences and safety (INFRA TH, Moscow, 2017)

12. S.N. Chernyshev, A.M. Martynov, Engineering researches 11, 32-43 (2011)

13. S.N. Chernyshev, A.M. Martynov, Mechanics of composite materials and designs, difficult and heterogeneous environments, 385-391 (2017)

14. T. Verminskaya, V. Zinatullin, A. Kuhta, I. Rubtsov, E. Chibisova, Almanac of modern science and education 7, 37-39 (2008)

15. D.Ju. Chunjuk, Industrial and civil building 9, 42-44 (2013) 